\title{
Statistical Methods - Does Anyone Really Use Them?
}

Bjarne Bergquist ${ }^{1}$ and Malin Albing ${ }^{2}$

${ }^{1}$ Department of Industrial Economics \& Social Sciences, Division of Quality \& Environmental Management, (corresponding author)

${ }^{2}$ Department of Mathematics

Luleå University of Technology, Sweden

Full address to corresponding author:

Bjarne Bergquist

Department of Industrial Economics \& Social Sciences, Division of Quality \& Environmental Management, Luleå University of Technology

97187 Luleå

Sweden

\section{Abstract}

Students taking courses in quality management at Luleå University of Technology receive extensive education in statistical methods. To improve the education and to understand what kind of competence students need when they graduate, a survey examining how and to what extent the methods Statistical Process Control, Capability Analysis and Design of Experiments are used by organisations hiring the alumni was preformed. The result shows that the students employed in the Swedish industrial sector witness a modest use. Use of statistical methods in other sectors hiring the alumni is uncommon. Lack of competence and resources within the organisations are stated as hindrances to expanded use. Conclusions from the study are that implementation techniques must be emphasized in the curriculum and that different types of courses should be given - practical, hands-on courses for engineers, managers and others working in organisations. Furthermore, courses offered at universities must have a strong focus on practical problems such as difficulties randomizing experiments and that graphical methods should be favoured.

\section{Keywords}

Capability index, Capability indices, Experimental design, Design of experiments, Statistical Process Control Survey, Use, Sweden 


\section{Introduction}

Statistical methods (SMs) such as Statistical Process Control (SPC), Capability Analysis (CA) and Design of Experiments (DoE) have been used for decades to improve the quality of processes and products in quality management, see Bergman \& Klefsjö (2003). The SMs have mostly been used in manufacturing industry, but also in other types of problems such as to understand customer needs and behaviour see Green \& Srinivasan (1978) or Gustafsson et al. (1999). The use of SMs are further amplified by recent quality management trends such as Six Sigma; see Harry (1994) or Hahn et al. (1999). SMs have also found applications in service, see Mundy et al. (1990), Kumar et al. (1996) or Mason \& Antony (2000), and this use is also amplified by the broadened focus of Six Sigma, see Hoerl (2001).

SMs have roles to play in different parts of organisational development, but the best of methods are of no value if no one uses them. In Swedish studies of the use of SMs performed in the mid 90s, the use ranged from nonexistent to moderate. In a survey by Deleryd (1996), the use of process capability measurements in Swedish industry was investigated and 97 of 205 respondents claimed to work with CA. However, an investigation of companies in the Swedish counties of North Bothnia and West Bothnia regarding the utilization of quality methods concluded that the use of DoE was around 6\% and that the use of SPC and CA was less than 5\% (Bäcklund et al. 1995). In a recent study by Gremyr et al. (2003), product development managers or quality managers from 105 manufacturing companies were telephone interviewed regarding the use of statistical methods in Swedish industry. A majority (53\%) of managers stated that their companies used DoE and more than $60 \%$ that their companies used SPC and CA respectively. The findings by Gremyr et al. (2003) are in agreement with a British study by Thornton et al. (2000), who investigated the use of SMs in 19 companies of which all used SPC, most used CA and about one third used some form of robust design methodology, including DoE.

Studies of the use of SMs outside the industrial sector are rare. A British survey by Redman et al. (1995) concluded that $18 \%$ of service organisations, private or public alike, used SPC. Witt \& Clark (1990) studied if SPC was used to improve quality in British tourism. The result was that 15 of 75 of respondents stated that use of SPC was frequent and another 9 respondents stated that use of SPC was occasional.

A problem in all the studies is of course what respondents define as "use". Is the occasional test of an SM enough for respondents to say that it is used, and are the definitions used in different investigations similar? 
Comprehension of SMs is vital if respondents should evaluate their use, and answers regarding use and applicability might be misleading if respondents lack proper method comprehension. Kotz \& Johnson (2002) state that the gap between practitioners and theoreticians in the field of $\mathrm{CA}$ is wide, that the gap has widened during the last 10 years. It appears likely that the same is true for SPC and DoE as well.

The authors of this paper are teaching quality management and applied statistical methods to Swedish engineering students. As teachers we often receive questions from students regarding how frequently the methods we teach are used. Other questions from students are how likely it is that, when they have graduated, they will transform their theoretical knowledge into practice at their workplaces. These questions are certainly legitimate and deserve a well-founded response. However, the responses we have given to such questions have generally been a mix of belief, knowledge and optimism. Optimism since we want the use to be high to retain high credibility. Nonetheless, in contact with Swedish industry, directly or indirectly, by supervising students, we were led to believe that use of SMs was less common than reported by Deleryd (1996) and Gremyr et al. (2003).

The apparent differences between the stated utilization of SMs based on interviews and surveys and student feedback were unsettling. Was the difference due to the limited access of our students or were they actually doing projects or diploma work in organisations that did not use statistical methods? Was use of SMs less frequent than previous studies had indicated, and if so why? Was the use of SMs in industry, service, research, or product development strong enough to be visible to new engineers entering their working life or were there only a few rare examples of this sort? To answer these questions, an investigation of the visibility of the use of these SMs in Swedish organisations was performed. Graduate students with method training in SMs could narrow the gap between theoreticians and practitioners. Thus, a follow-up of how organisations with which they had worked use SMs was considered interesting.

\section{Purpose}

The main purpose of the investigation was therefore to determine how our alumni would describe the frequency and use of SMs in their workplaces and also how the SMs are used. Secondary purposes were to seek answers to what motivated organisations to implement or not implement SMs, to seek differences in use related to organisational types, and to find out what was needed to increase the use. 


\section{Method}

The survey, executed as an inquiry, was limited to alumni students who had taken their final courses in quality management at Luleå University of Technology. The sampling frame was based on students who had taken university courses covering these specific SMs with a length of at least three full-time weeks. It was therefore possible to ensure that the respondents were well aware of our views and definitions of these methods, and explanations of SMs in the questionnaire could be held short. Our hope was that the response rate should be high, as the respondents were our own alumni. However, a possible bias if results were compared to general use, for instance industrial or Swedish use, could be that the respondents with method training would be more prone to seek work in companies interested in these skills. Still, the target population was considered ideal to answer the question: "How likely is it that graduated students meet SMs?".

The sampling frame was a mix between a convenience sampling and a total investigation, in such a way that the total population of our alumni was included. Since one of the reasons for starting the investigation was to examine how likely it is that alumni will come into contact with SMs in their workplaces, the sampling frame was considered relevant. Using another type of sampling frame and selection method, e.g. a randomly chosen sample from a database containing Swedish companies would enable different types of general statements, but would not enable commenting the alumni students. It was also considered more important to use a respondent group with method training on the basis of the questions we wanted answered.

A preliminary version of the questionnaire was tested on a group of researchers at Luleå University of Technology teaching questionnaire design and analysis. The three sections of the questionnaire focused on SPC, CA and DoE, respectively. Each section included questions where respondents rated the organisational use of each SM using Likert scales. The degrees of use of the SMs were divided into seven statements about each company or organisation with which they were acquainted ranging from the SM not being relevant for the processes of the workplace to the SM being used systematically in all processes. In addition, the questionnaire included open questions aiming at understanding why the SMs were used, how results are used, and what the obstacles are to increasing the frequency of use. The questionnaire was designed so that respondents could rate the use of several organisations they had worked with. 
Unreachable alumni and alumni without working experience were excluded, giving a sample size of 94 respondents. The first round of questionnaires was sent out in November 2004 and the respondents were given three weeks to answer the questionnaire, resulting in 22 responses. A reminder where each missive letter was handsigned by the researchers and the name of the respondent was pre-written was sent in December 2004, which resulted in 40 additional responses. A second reminder was sent in January 2005, resulting in six more responses. This gives a total of 68 responses and a response rate of $72 \%$. In an effort to reduce speculative answers, only responses where the respondent had seen an occasional or more frequent use were analysed in connection to questions such as why the organisation had implemented the SM.

Affinity diagrams were used to group the answers of the open questions. Open answers were also separated on the basis of the respondents' answers to the closed questions, enabling comparison of open answers of respondents reporting rare or no use of SMs to open answers of respondents reporting frequent use.

\section{Results}

The 68 respondents gave their opinion of how the SMs were used in a total of 98 Swedish workplaces. In 83 of the workplaces, the respondents stated that they had enough insight to judge the use of SMs. The workplaces were classified as small or large based on the number of employees. If the number was larger than 50 , the organisation was considered large. The workplaces were also separated into service or industrial type organisations, see Table 1.

\section{Quantitative results}

A majority of the respondents indicated sporadic or no use of the SMs in the organizations where they had worked, and this was independent of the SM in question, see Figure 1. Of the 36 workplaces where SPC had at least been tested, only one company was said to use SPC systematically in all relevant processes and 6 companies were said to use SPC in most of the relevant processes. For CA (21 workplaces) and DoE (18 workplaces), none of the companies was reported to use the SM systematically in all relevant processes, and only at three companies was the use said to be in most of the relevant processes. 
Table 1 is a two - way representation of the use of SMs, categorized by organizational type and organizational size. "Use" in Table 1 is defined as one SM has at least been tested (numbers within parenthesis is number of organisations within each category).

(Approximate placement of Figure 1.)

There is a difference between how respondents estimated the use of SMs in their organizations depending on the size of the organization. Respondents within large organisations see use of SM:s more often. The use in service organisations is less frequent than in industrial organisations. Furthermore, there is no clear tendency for neither small nor large organisations to be either industrial or service types and thus, the effect of company size does not explain the more frequent use in larger firms compared to that in small ones and vice versa; the size effect does not explain why industrial firms are more frequent users.

(Approximate position of Appended Table 1)

Depending on SM, 48\% (SPC), 54\% (CA) and 55\% (DoE) the respondents that had worked in the non-industrial sector had the opinion that use of SMs was irrelevant for the type of work performed there. For the industrial organisations, the SMs were classified as irrelevant for $11 \%$ (SPC, CA) and $18 \%$ (DoE).

\section{Qualitative results $S P C$}

Based upon the open answers of the respondents that had seen use of the SMs (predominantly large manufacturing firms), a conclusion is that the large majority of companies had the motive to reduce or control variation when SPC and control charts were introduced. Twelve respondents stated that SPC results were used by the company to improve processes; five respondents stated that the results from SPC were not used at all. When asked what prevents companies from increasing the use of SPC, 13 respondents thought that a combination of lack of education and training, lack of time and lack of proper SMs was the major hindrance. Three stated that fear of change was the main obstacle. Single answers pointed to laziness, too theoretical a method, too small series, and a general statement that SPC is hard to apply. 


\section{Qualitative results $C A$}

Compared to reasons for introducing SPC, the purpose of introducing capability measures shifted more and ranged from needs to validate and improve processes (six answers), validate supplier processes (two answers), QS9000 demands (two answers) and improve product quality (two answers). Of capability indices, $\mathrm{C}_{\mathrm{p}}$ and $\mathrm{C}_{\mathrm{pk}}$ dominated the use and a usual acceptance criterion was to have $\mathrm{C}_{\mathrm{pk}}>1.33$. Three workplaces used tougher acceptability criteria $\left(C_{p}>1.67\right)$ for new processes. Work on improving processes was usually initiated (eight of ten) when processes were not capable. The respondents gave similar reasons for what prevented further use of CA as for what prevented further use of SPC.

\section{Qualitative results DoE}

The reasons for introducing DoE was even more varied and some excerpts were: “...need to reduce process variation”, “...too many variables for one-factor-at-a-time type experiments”, “...interested in new technology.”, “...need for improving process quality”. All respondents (11) that discussed how companies had worked with DoE stated that full or reduced factorial designs were used. One company also used split-plot experiments, one used mixture experiments and one had used Taguchi type experiments. Albeit split-plot experiments were only used by one company, all but one respondent stated that the experimental arrangement usually was non-random and that this was due to difficulties adjusting certain factors. Lack of management competence as well as engineering competence was stated as the main obstacle to a more frequent use of DoE. However, one respondent stated that DoE was too resource demanding.

\section{Reliability and validity}

Other surveys measuring the use of statistical or other quality related SMs have observed response rates in the 15 - 27 \% range, see Witt \& Clark (1990), Mathews et al. (2001), Redman et al. (1995) or Deleryd (1996). Response rates of alumni surveys are often in the 32-36\% range, see Porter \& Umbach (2001). The response rate of the study $(72 \%)$ is considerably higher than that of other surveys of statistical methods. The response rate was higher in the first reminder than in the first survey, which was probably due to the personal touch with handwritten names and signatures of the researchers. The high response rate of this survey compared to that of other studies is most likely related to the selected response group in combination with the personal touch. The first survey and first reminder included enough responses to estimate if the respondents had answered differently in the reminder than in the first survey. The differences of stated use were compared for all SMs; for a SPC exam- 
ple see Figure 2. The profiles of the two groups of answers were considered fairly equal, and this result was about the same for all SMs. We thus assume that the answers were not dependent upon whether the respondent had answered directly or more reluctantly. Led by this result, we assume that answers of non-respondents would not have led to markedly different results.

Approximate position for Figure 2

Since the study by Bäcklund et al. (1995) showed little use of SMs in Sweden's northernmost counties, North Bothnia and West Bothnia, a concern was that results might be hard to analyze, if the distribution of the location of workplaces was highly skewed toward the northern part of Sweden. In Figure 3, the workplaces in the study have been marked. The spread of the workplaces is a fair representation of the density of the Swedish population and the manufacturing industry in particular. However, a few locations are overrepresented. One is Luleå from where our alumni had graduated, where 20 workplaces were situated. A random sample of Swedish engineers would perhaps have resulted in 2 workplaces in Luleå. Gothenburg (13 workplaces) and the Gothenburg region is the location of the Swedish centre for car and truck manufacturing, which would explain the overrepresentation here. Stockholm (25 workplaces) and the Stockholm region have a large number of consultancy and service firms and is also represented with a larger share of workplaces. Västerås (7 workplaces) holds a concentration of $\mathrm{ABB}$ companies and is also a major employer of our alumni students. The southernmost part of Sweden is underrepresented. Still, 74\% of the workplaces were situated south of the North Bothnian/West Bothnian border, and therefore we believe that the result is valid in a larger context.

\section{Approximate position of Figure 3}

The answers of respondents that had stated that they were working at the same workplace were also compared and the differences in answers were considered small. A conclusion is therefore that the results regarding the investigated workplaces are valid.

\section{Discussion}

The sampling frame

Compared to the regular Swedish population or to the average engineer, our alumni students have a better knowledge of the SMs. We thus expect them to be more often seen in organisations that work with these meth- 
ods or feel the need for them, as their background would fit the offered job descriptions. The workplaces of alumni groups are also highly skewed towards work in the private sector and in the manufacturing industry. It is in the manufacturing industry that we see the most frequent use of SMs. A conclusion from this is that if the sample had been a random sample of Swedish organisations, the frequency of use would have been much lower. Our conclusion related to earlier studies by Deleryd (1996), Bäcklund et al. (1995) or Gremyr et al. (2003) is that many industrial companies have probably tried some of the methods once or twice, but that regular use is much less frequent. We also believe that it is vital that respondents have some knowledge of the SMs in question or else their answers will be more of a guessing game. This may be the case when managers or quality engineers are surveyed, as these often have no method training.

\section{Use of SMs in different sectors}

We do not see much evidence that the SMs are used in the service sector. In fact, many of our alumni believe that SMs do not fit the operations in those workplaces. Although we feel differently, we recognize that most student texts take most examples from the manufacturing industry. The result shows that we need to prepare students better for work in this sector, with actual examples from this sector and with implementation problems and solutions

One result of this investigation was that smaller organisations were less prone to use SMs. According to Deleryd et al. (1999), the management of many smaller organisations does not have a sufficient theoretical background to see the potential, and the smaller organisations lack resources in terms of time, personnel and statistical software. Our survey supports this statement.

The respondents working in the manufacturing industry also thought that lack of knowledge was a main obstacle to expanding the use of the methods. Many also said that their processes were more difficult compared to examples studied at university. Short production runs, autocorrelation or difficult-to-control factors were mentioned. Penzias (1989) and Bisgaard (1991) argue that it is the statistics taught to engineers at universities that is too theoretical, so that graduated students have little use for or cannot connect the statistics learned to the applied problem at hand. Although we believe that the nature of the statistics included in the quality management curriculum is applied rather than theoretical, most, or all, of the people the alumni meet at their workplaces do not have the same deep knowledge of SMs. Thus, the alumni often have to implement the SMs themselves if they are to be used, as well as train the staff in how to use them. What they can teach fellow employees with limited 
resources is probably restricted to basic use of the SMs, for instance how to operate a control chart and what to do when the chart gives an alarm.

There may be several reasons for the low interest in using SMs in non-manufacturing firms. Wood (1994) discusses the use of SPC in the service sector and concludes the following: it is necessary to measure important quality characteristics, which may be more difficult in service than in manufacturing. There is also a risk that SPC would be used to assign guilt and not to improve the process. Redman et al. (1995) and Witt \& Clark (1990) found that between 18 and $30 \%$ of British service organisations use SPC. Compared to the result in this investigation, at 7 of 35 workplaces (20\%) our alumni's saw that SPC had been used, but only in three workplaces $(9 \%)$ was SPC used, not as a test but on an occasional basis.

The textbooks on SMs are filled with examples from manufacturing or process industries and examples from services are rare, see Montgomery (2005a), Montgomery (2005b), Wheeler (1995), Ryan (2000) or Schmith \& Launsby (1994). If students are to use methods outside industry, teachers need to refocus and start using examples from service and design in DoE and SPC courses. The textbooks on DoE should highlight that it has a place in design as well as in manufacturing, both in conceptual design including customer evaluation of attractiveness of consumer products using ConJoint Analysis, see Green \& Srinivasan (1978) or Gustafsson et al. (1999). Student texts should not neglect Robust Design Experiments in creating products and processes that are robust versus variation in for instance raw materials or product use, see Taguchi (1986) or Montgomery (2005b).

\section{Conclusions}

A major obstacle to using SMs is lack of knowledge and competence. Knowledge of statistics or of SMs is not the same as competence in implementing them into real applications. Student texts and course curricula should discuss not only how factors are selected but also who to involve and how to involve them. To have the production personnel involved and not feeling threatened that the control charts are used to assign blame but to improve processes is vital for the success of such implementations. A point to consider is that implementation problems of SMs should be included in method training. This is because it is likely that the organisation in which the graduate is going to work is unlikely to have an operating SM and it will thus be the business of the graduate to implement it. 
All implementation efforts cannot be laid upon the shoulders of fresh engineers, since they may not have the platform within the organisations to change the way the work is done. The senior engineers or managers of organisations will often be the ones that have the authority to implement SMs. However, these people may have forgotten the theoretical statistics learnt at university, if these topics were studied at all. Here we see the need for two different types of education. We need courses with a hands-on approach - how to perform experiments, measure capability and control processes without so much emphasis on statistics. At universities we need to focus not only on the statistics involved, but also target the practical aspects of SMs; what could go wrong, who will struggle against implementations, and what are the threats to success.

For basic courses in DoE, one may not need several ways to find out if effects are active, because if one method says a factor is active while the other says it is not, the results may confuse rather than enlighten. We believe that graphical methods like normal probability plotting (see Daniel, 1959) are more intuitive than ANOVA-tables and confidence intervals (graphical methods to present results should also be used more in conjunction with capability studies, see Deleryd \& Vännman, 1999). At all levels of teaching statistics, we must also discuss differences between what is statistically significant and what is practically relevant. Is the effect large enough so that the factor has to be held at a certain, perhaps more expensive level?

In more advanced courses in DoE, we must discuss when we need to randomize and what conclusions may be drawn if randomisation is restricted (as it often is) and introduce split-plot techniques. If experimental variation is large and the results are unclear, what should we do:

If additional experiments are cheap?

If additional experiments are expensive?

Could one, for example, use a priori knowledge such as that factor effects are acting in the expected direction to adjust significance thresholds? Are Bayesian methods suitable?

Computer programs often simplify work both in the design phase and in the analysis phases of working with SMs. Experimental designs and sampling plans are rendered in the space of a moment, which is fine if one has enough knowledge of how to specify the program inputs correctly. Computer analysis does offer enormous possibilities of performing analyses of performed tasks (analysis of effects, residuals, normality, skewness and a multitude of other tests). For the experienced user, the large number of possibilities is excellent. The inexperienced user may treat statistics programs as black box magic, and the multitude of different type of tests is a prob- 
lem. If students are taught only to interpret computer printouts of advanced statistical programs, they may miss the opportunity to develop an understanding of the underlying mathematics of, for instance, exponentially moving average control charts, designing reduced experimental plans or calculating effects. Students may start working in organisations that, for one reason or another, do not have the programs in question. We propose that spreadsheet programs such as Ms Excel be put to greater use, see Beauchamp \& Youssef (1998). Here students may see first hand what happens when a disturbance enters the data of control charts or how effects are calculated. These programs are also very common in any type of organisation and hence the knowledge and computer scripts of the student could be put to use wherever the student is employed.

We also need to apply the theoretical SM knowledge already in the course work. Teachers should collect appropriate data or problems for students to work with. Students should also be encouraged to work with problems of their own, for instance by optimizing recipes or testing optimal settings of the video game of their choice. We feel that it is hard to discuss practical problems theoretically, if the students do not have first-hand experiences that they can relate the discussions to. Naturally, this is true of courses at all levels.

The statistics community should also put research efforts into developing our SMs so that they are robust against misuse and clarify the boundaries where methods might be abused and when method descriptions should be followed meticulously.

Acknowledgements

This work was financed by the Swedish Research Council under grant number 621-2002--3823

\section{References}

Bergman, B., \& Klefsjö, B. (2003) Quality from Customer Needs to Customer Satisfaction (Lund, Sweden, Studentlitteratur)

Beauchamp, Y., \& Youssef, Y.A. (1998) An effective approach to teach Design of Experiments (DOE) using calculation-and-analysis worksheets and computerized spreadsheets, Computers and Industrial Engineering, 35(3-4), pp. 643-646 
Bisgaard, S. (1991) Teaching statistics to engineers, The American Statistician, 45(4), pp. 274 - 283.

Bäcklund, M. Hellsten, U. \& Hjertström, E. (1995) Kvalitetsarbete i Norrbottens och Västerbottens län (Research report, Luleå University, Division of Quality Technology, 1995:3) (in Swedish)

Daniel, C. (1959) Use of half-normal plots in interpreting two level experiments, Technometrics, 1(4), pp. 53-70

Deleryd, M. (1996) Process Capability Studies in Theory and Practice (Licentiate thesis, Luleå University of Technology, 1996:06 L)

Deleryd, M., Garvare, R., \& Klefsjö, B. (1999) Experiences of implementing statistical methods in small enterprises, The TQM Magazine, 11(5), pp 341-351

Deleryd, M. \& Vännman, K. (1999) Process capability plots - A quality improvement tool, Quality and Reliability Engineering, 15(3), pp. 1-15

Green, P.E., \& Srinivasan, V. (1978) Conjoint analysis in consumer research: Issues and Outlook. Journal of Consumer Research, 5(9), pp. 103-123

Gremyr, I., Arvidsson, M., \& Johansson, P. (2003) Robust design methodology: Status in Swedish manufacturing industry, Quality and Reliability Engineering International, 19(4), pp. 285-293

Gustafsson, A., Ekdahl, F., \& Bergman, B. (1999). Conjoint analysis - A useful tool in the design process, Total Quality Management 10(3), pp. 327-343

Hahn, G.J., Hill, W.J., Hoerl, R.W. \& Zinkgraf, S.A. (1999) The impact of Six Sigma improvement-A glimpse into the future of statistics. The American Statistician, 53, pp. 208-215.

Harry, M.J. (1994) The vision of Six Sigma: a roadmap for breakthrough (Phoenix, AZ, Sigma Publishing Company) 
Hoerl, R.W. (2001) Six Sigma black belts: What they need to know (with discussion), Journal of Quality Technology, (33)4. pp.391-435

Kotz, S., \& Johnson, N.L. (2002) Process capability indices - A review, 1992 - 2000 - with discussion, Journal of Quality Technology, (34)1,, pp. 2-53,

Kumar, A., Motwani, J. \& Otero, L. (1996) An application of Taguchi’s robust experimental design techniques to improve service performance, International Journal of Quality \& Reliability Management, (13)4, pp. 85-88

Mason, B. \& Antony, J. (2000) Statistical process control: An essential ingredient for improving service and manufacturing quality, Managing Service Quality, 10(4), pp. 233-238

Mathews, B.P., Ueno, A., Lopez Periera, Z., Silva, G., Kekal, T., \& Repka, M. (2001) Quality training: Findings from a European survey, The TQM Magazine, 13(1), pp. 61-71

Montgomery D.C. (2005a) Introduction to Statistical Quality Control, $5^{\text {th }}$ Edition, (New York, NY, John Wiley \& Sons)

Montgomery, D.C. (2005b) Design and Analysis of Experiments, $6^{\text {th }}$ Edition (New York, NY, John Wiley \& Sons)

Mundy, R.M., Passarella, R., \& Morse, J. (1990) Applying SPC in service industries, Survey of Business, 21(2) pp. 24-29

Penzias, A. (1989) Teaching statistics to engineers, Science, 244(4908), p. 1025

Porter, S.R., Umbach, P.D. (2001) What works best? Collecting alumni data with multiple technologies, in: AIR 2001 Annual Forum Paper, pp. 1-23 
Redman, T., Mathews, B., Wilkins, A., \& Snape, E. (1995) Quality management in services: Is the public sector keeping pace, International Journal of Public Sector Management, 8(7), pp. 21-34

Risberg-Elkjaer, M., \& Bisgaard, S. (1998) The Use of experimental design in the development of new products, International Journal of Quality Science, 3(3), pp. 245-274

Ryan, T.P. (2000) Statistical Methods for Quality Improvement (New York, NY, John Wiley \& Sons)

Schmidt, S.R., \& Launsby, R.G. (1994) Understanding Industrial Designed Experiments (Colorado Springs, CO, Air Academy Press)

Taguchi, G. (1986). Introduction to quality engineering - design quality into products and processes. (Tokyo, Asian Productivity Organization).

Thornton, A.C., Donelly, S., \& Ertan, B. (2000) More than just robust design: Why organizations still contend with variation and its impact on quality, Research in Engineering Design, 12(3), pp. 127-143

Wheeler, D.J. (1995) Advanced Topics in Statistical Process Control (Knoxville,TE, SPC Press Inc)

Witt, C.A., \& Clark B.R. (1990) Tourism: The use of production management techniques, The service Industries Journal, 10(2), pp. 306-319

Wood, M., (1994), Statistical methods for monitoring service processes, International Journal of Service Industry Management 5(4), pp53-68 


\section{Appended figures}

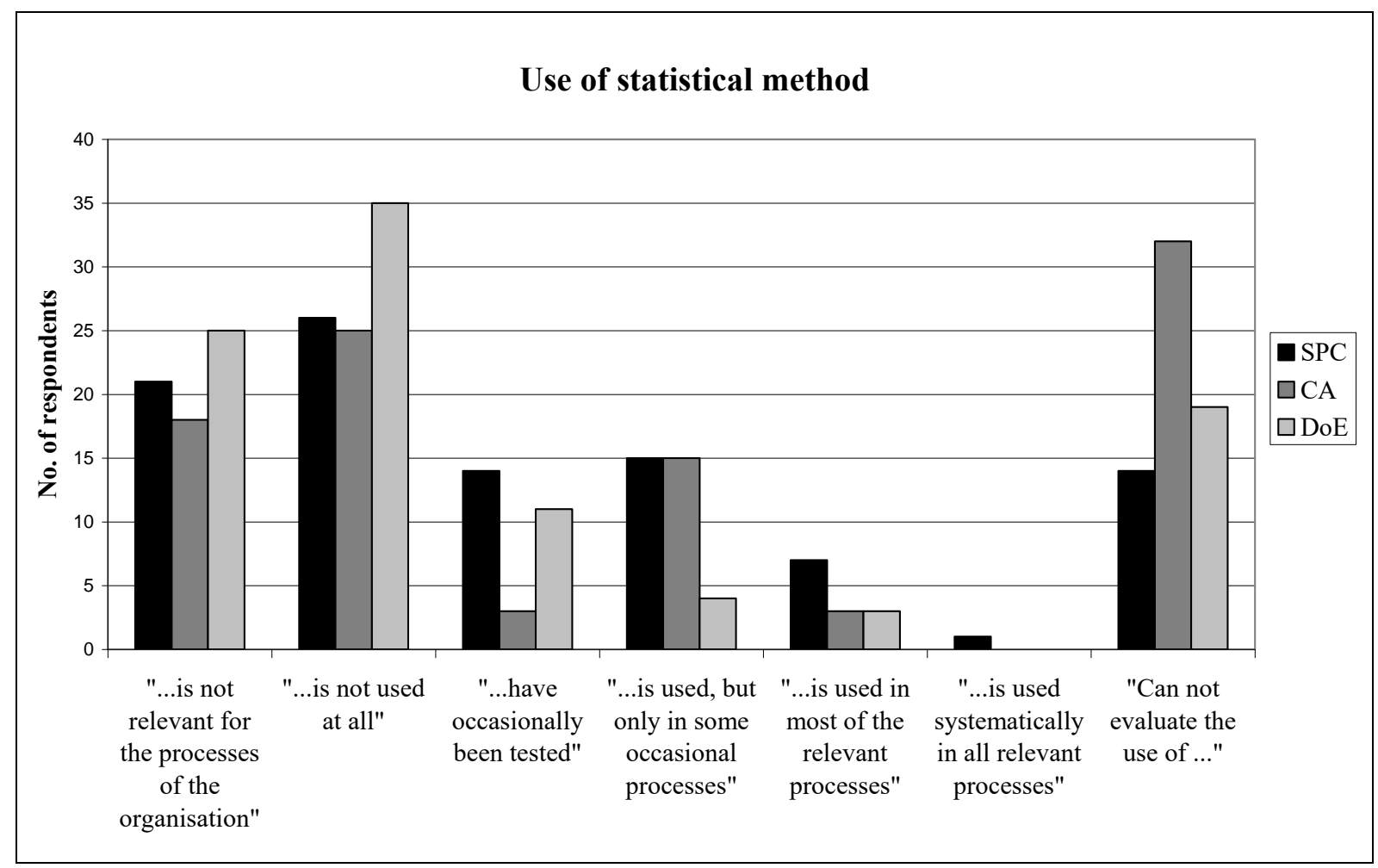

Figure 1. Use of statistical methods in the organisations where the respondents have worked. 


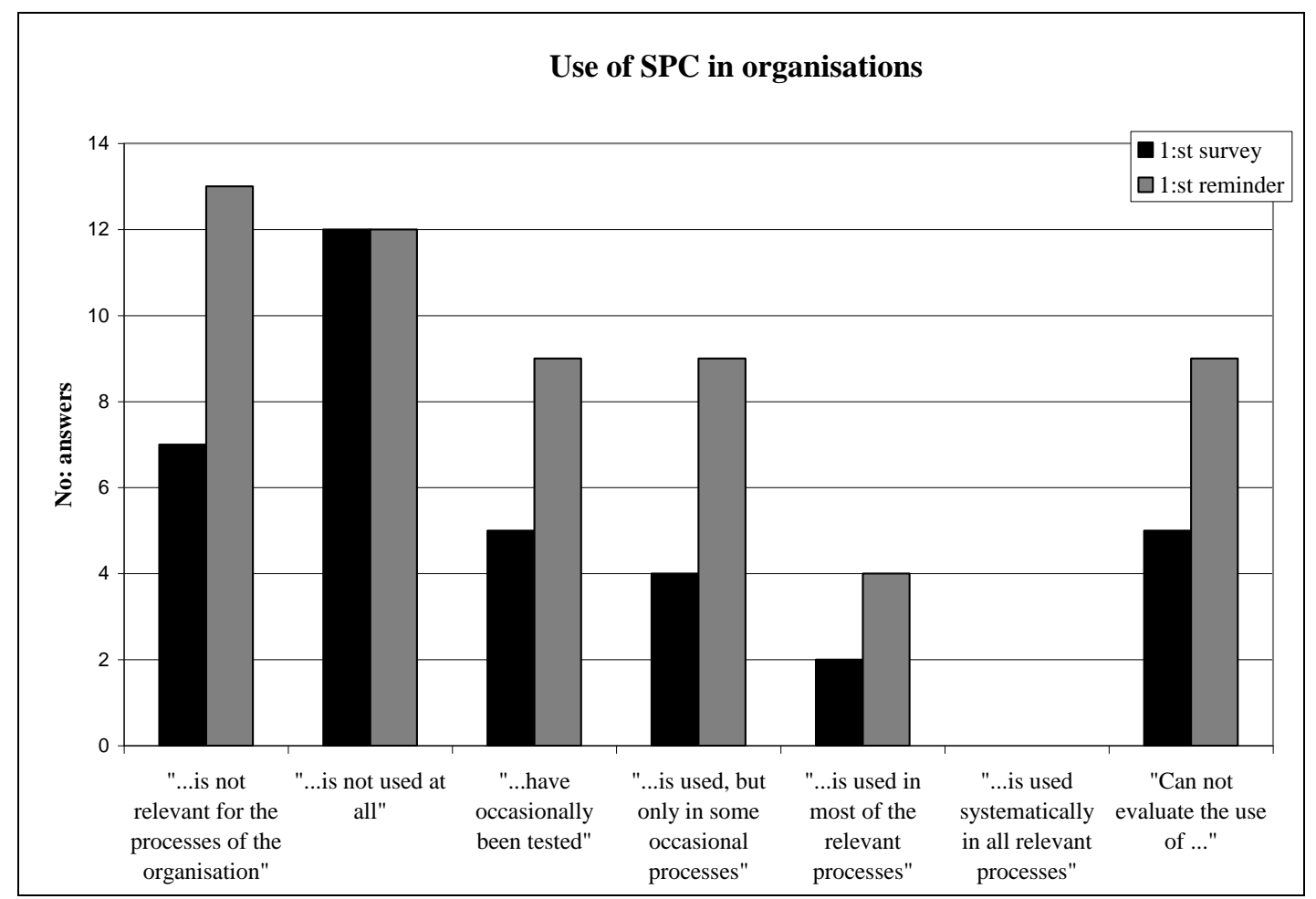

Figure 2. Use of SPC in organisations where respondents have worked in the first survey and the first reminder survey. 


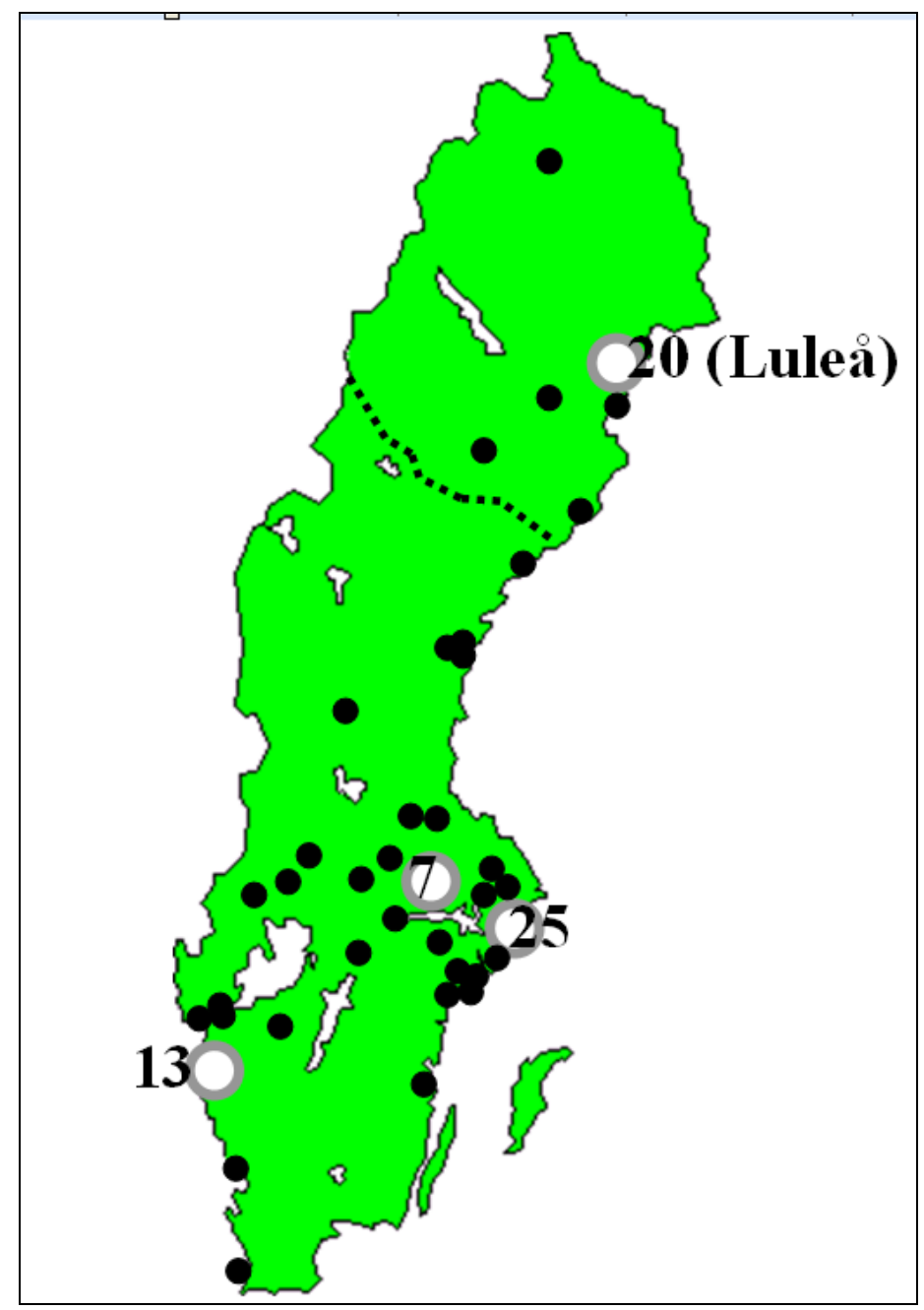

Figure 3. Map of Sweden with locations of workplaces in the study. Black dots represent one workplace, larger white dots represent multiple workplaces, with the numbers shown. The dotted line represents the southern border of the two northern counties, West Bothnia and North Bothnia. 
Table 1. The numbers of organisations that have been classified by the respondents to use statistical methods. Cell numbers represents use of SMs within category (number of organisations within category in parenthesis).

\begin{tabular}{l|l|l|l} 
& $\begin{array}{l}\text { Small org. } \\
(<50 \text { employees })\end{array}$ & Large org. & Total \\
\hline Industry & $1(7)$ & $31(43)$ & $32(50)$ \\
\hline Non-industrial & $0(9)$ & $7(26)$ & $7(35)$ \\
\hline Total & $1(16)$ & $38(69)$ & $39(85)$ \\
\hline & & &
\end{tabular}

